\title{
Pretrial Detention and the Costs of System Overreach for Employment and Family Life
}

\author{
Sara Wakefield, ${ }^{a}$ Lars Højsgaard Andersen ${ }^{b}$
}

\author{
a) Rutgers University; b) ROCKWOOL Foundation Research Unit
}

\begin{abstract}
Using unique Danish register data that allow for comparisons across both conviction and incarceration status, this article analyzes the association between pretrial detention and work, family attachment, and recidivism. We find that pretrial detention may impose unique social costs, apart from conviction or additional punishments. Most notably, men who are detained pretrial experience poorer labor market trajectories than men who are convicted of a crime (but not incarcerated). Importantly, this result holds even for men who are detained pretrial but who are not convicted of the crime. Consistent with prior research, we also find that pretrial detention is unrelated to later family formation but might disrupt preexisting household arrangements. Finally, the associations between pretrial detention and work and family life are not counterbalanced by reductions in recidivism.
\end{abstract}

Keywords: pretrial detention; consequences of incarceration; employment; family; recidivism

Citation: Wakefield, Sara, and Lars Højsgaard Andersen. 2020. "Pretrial Detention and the Costs of System Overreach for Employment and Family Life." Sociological Science 7: 342-366.

Received: April 18, 2020

Accepted: June 20, 2020

Published: August 17, 2020

Editor(s): Jesper Sørensen, Sarah Soule

DOI: $10.15195 /$ v7.a14

Copyright: (C) 2020 The Author(s). This open-access article has been published under a Creative Commons Attribution License, which allows unrestricted use, distribution and reproduction, in any form, as long as the original author and source have been credited. (C) (i)

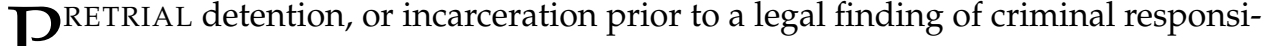
1 bility, is common the world over. In most countries, between 10 and 40 percent of all prisoners are pretrial or remand detainees. The United States holds the largest absolute number of detainees, but the Americas and parts of Asia have increased their rates of pretrial detention more recently (Heard and Fair 2019; Walmsley 2016a). Pretrial detention is thus common but represents an understudied experience in the broader literature on the social effects of criminal justice expansion.

We analyze the effects of pretrial detention, with and without conviction, to more clearly distinguish effects that flow from the imposition of a criminal label from those that flow from incarceration and additional punishment experiences. Specifically, we exploit the detailed nature of register data from Denmark to compare work, family, and recidivism outcomes for four groups that are difficult to isolate from one another in other available data sources: (1) those who are detained pretrial yet not convicted, (2) those who are convicted and serve their full sentence pretrial, (3) those who are detained pretrial and then sentenced to an additional term of imprisonment, and (4) those who are pretrial detained and then sentenced to other sanctions (primarily probation). We compare these four groups with a group of people who are convicted but never incarcerated.

We find that pretrial detention may impose unique social costs, apart from conviction or additional punishments, and reduces labor market and family attachments with no corresponding reduction in recidivism for detainees, to the degree that our results can be given causal interpretation. Our results highlight an important consequence of system overreach in the mass incarceration era; men who arguably should not have been incarcerated pretrial, and hence should not have 
to suffer any damaging effects of this experience, nonetheless experience both the denial of liberty associated with incarceration as well as longer-term harms once released.

In the sections to follow, we first describe pretrial detention generally and in the Danish context specifically. We next describe our analytic strategy and the difficulties of establishing salient comparisons in the absence of random assignment to differential criminal justice outcomes. We then offer evidence on the relationship between pretrial detention and labor market outcomes, family attachment, and recidivism. In so doing, we aim to broaden the lens of "collateral consequences" research to include forms of carceral contact, like pretrial detention without conviction, that are often hidden from view in contemporary data sets.

\section{Broadening the Landscape of Incarceration}

Increases in incarceration across Western democracies are well known. In the most extreme example of criminal justice expansion, the imprisonment rate in the United States grew from a relatively stable 105 per 100,000 to a peak of 504 per 100,000 in 2008. The widespread experience of arrest (Brame et al. 2011) and entanglements related to misdemeanors (Kohler-Hausmann 2013) further detail the long reach of the American criminal justice system. Criminal justice expansion, albeit smaller in magnitude, is evident in the incarceration rates across other Western democracies, including England and Wales (148 per 100,000), the Netherlands (69 per 100,000), and, our research site, Denmark (61 per 100,000) (Walmsley 2016b). The rapidly expanding literature on the use of incarceration globally suggests that overincarceration results in widespread social harms (Comfort 2007; Ramakers et al. 2014; Wakefield and Uggen 2010; Wildeman et al. 2014). Scholarship on high incarceration rates is focused on relatively few countries, however, with the lion's share commenting on the United States, reflecting the extreme punishment rates there. Yet even in U.S. states with lower incarceration rates or countries with milder penal climates, the high rate of pretrial detention and its harsh conditions often stand out (Barker 2013; Hood and Schneider 2019; May et al. 2014; Menefee 2018; Smith 2012; Wildeman and Andersen 2020).

Pretrial detention is legally permissible to protect the public from potentially dangerous people during the adjudication process and ensure that defendants appear for trial; such justifications are common across jurisdictions. Localities often differ, however, with respect to the threshold and rate of detention (Walmsley 2016a), the use of money bail or other conditions of release (Hood and Schneider 2019; Scott-Hayward and Ottone 2018; Stevenson 2018), and the conditions of pretrial confinement (Smith 2012; Turney and Connor 2019). Despite such variation, pretrial detention everywhere represents a fundamental and relatively unexamined denial of liberty, with no corresponding finding of criminal responsibility to justify

its use. In an era when millions are exposed to the pains of incarceration for increasingly lengthy periods without a finding of criminal responsibility (e.g., Appleman 2012; Rizer and Meares 2020), the social consequences of pretrial detention are of substantial importance. 
Research on the consequences of pretrial detention, relative to other forms of incarceration, for social outcomes is scant, although a robust literature has focused on the legal basis for its use (Appleman 2012; Mitchell 1969); influence on guilty pleas, conviction, and incarceration (Heaton, Mayson, and Stevenson 2017; Lowenkamp, VanNostrand, and Holsinger 2013; Rankin 1964; Stevenson 2018; Williams 2003); the extralegal predictors of detainment (Demuth 2003; Schlesinger 2005; Spohn 2009, Ulmer 2012); and the role money bail systems play in punishing poverty (Gupta, Hansman, and Frenchman 2016; Hood and Schneider 2019; ScottHayward and Fradella 2019). Most relevant for the analysis to follow, critics of pretrial detention link it to worse case outcomes, often especially among low risk defendants (e.g., Goldkamp 1983; Lowenkamp et al. 2013; Stevenson 2018; Dobbie, Goldin, and Yang 2018). Such findings can be interpreted in a multitude of ways, of course. To the extent that dangerous or especially high-rate offenders are adequately selected for pretrial detention, we might expect that those who are detained may be more likely to recidivate. It remains the case, however, that research on pretrial detention has tended to focus on case outcomes and the management of risk, rather than on the potential harms to other facets of social life once the criminal justice system is left behind (but see Dobbie et al. 2018; Heaton et al. 2017; Scott-Hayward and Fradella 2019).

The lack of research on the social consequences of pretrial detention contrasts sharply with a robust literature on the social consequences of postconviction incarceration. Incarceration and criminal conviction worsen labor market outcomes for the formerly incarcerated (Andersen 2015; Apel and Sweeten 2010; Harding et al. 2018; Pager 2003; but see Loeffler 2013). The same is true for family outcomes; a number of studies document the strains associated with incarceration for romantic relationships (Comfort 2007; Fallesen and Andersen 2017; Massoglia, Remster, and King 2011), but few of them focus on pretrial detention specifically, and it is often poorly measured (but see Apel 2016; Comfort 2016; Harding et al. 2018; Sugie and Turney 2017).

A more recent study (Dobbie et al. 2018) focused squarely on pretrial detention offers evidence on two of the three outcomes of interest to this article. Leveraging variation among bail judges in the likelihood of imposing pretrial detention in two U.S. jurisdictions, Dobbie et al. (2018) found those who were detained pretrial were more likely to plead guilty, were less likely to be employed, and earned less if employed following release. ${ }^{1}$ Whereas pretrial detention was linked to worse employment outcomes, it failed to reduce recidivism. Such findings highlight the mixed nature of pretrial detention; although it does hold defendants in place prior to case disposition, it appears to be relatively unconnected to either prior criminal history or risk of future crime.

A critical distinction between the Dobbie et al. study and ours, however, pertains to which marginal defendant is analyzed. Dobbie et al. analyze the effects of pretrial detention for the subgroup of defendants and cases where pretrial detention is based on a qualitative evaluation by the judge and where the judge's pretrial detention decision could-depending on the judge's leniency—go either way. They do so because their identification strategy is very strong for this subgroup. Most pretrial 
detention decisions do not fall on this margin, however, as the characteristics of some defendants and/or cases (almost) always lead to pretrial detention.

In our study, as we explain in detail below, we compare defendants who differ in their conviction, pretrial detainment, and sentencing outcomes. As such, although our analytical strategy relies on common trends assumptions (which are fundamentally untestable) and does not benefit from semi-random assignment of pretrial detention, results from our analyses provide new knowledge on the potential consequences of pretrial detention in cases where pretrial detention is either justified by later case outcomes or not. From a policy perspective, it is imperative that we have knowledge on this margin, as such knowledge is instructive on the consequences of system failure in the form of overzealous detention decisions. In the analysis to

follow, we add much needed detail on the relationship between pretrial detention and the social consequences of incarceration.

\section{Context, Data, and Methods}

\section{Context}

Pretrial detention is common, but less widely appreciated is that it often serves as a more severe form of incarceration (May et al. 2014; Smith 2012; Toman, Cochran, and Cochran 2018; Turney and Connor 2019). Pretrial detainees are often held in local jails or detention centers, rather than in prisons, and the conditions of confinement may differ substantially. The population of local jails and pretrial detention centers tends to be more heterogenous and overturn rapidly, resulting in conditions that are far less stable relative to prisons. Partially as a result of the high rate of turnover, those held in pretrial detention have access to fewer services and programs as well as fewer opportunities for connection to family and friends outside. Finally, pretrial detention facilities globally are often characterized by high rates of solitary confinement, severe mental health problems among their residents, and unsafe conditions (Haney et al. 2015; Smith 2006; Wildeman and Andersen 2020).

In the analysis to follow, we utilize registry data from Denmark. Much like the distinctions drawn between the conditions of confinement in prisons relative to jails, pretrial detention in Danish "remand" facilities represents a more harsh experience relative to that experienced by convicted prisoners (Smith 2012; Smith and Jakobsen 2017). During postconviction incarceration in Denmark, incarcerated people are offered a range of resocialization initiatives, such as education and employment training. Imprisonment in Denmark is structured so as to resemble life outside prison (deprivation of freedom is the punishment, rather than enduring harsh prison conditions), and imprisoned people are paid a small salary for participating in resocialization initiatives, allowing them to buy groceries and cook their own meals in common prison wing kitchens. The average sentence length in Denmark was eight months in 2016, but more than half the sentences were shorter than four months that year (Danish Prison and Probation Service 2017).

In contrast, pretrial detention in Denmark is marked by incarceration in separate pretrial detention centers (arresthuse) or in pretrial detention wings of actual prisons, 
and private cells. Pretrial detention may only lawfully be imposed on people charged with crimes that can lead to a prison sentence exceeding 1.5 years, and pretrial detention must be approved by a judge and in relation to the specific risks related to the ongoing police investigation (such as the risk collusion) and/or the detainee (such a flight risk or a history of repeat offenses). The judge can approve pretrial detention for up to four weeks, at which point the detainment must be renewed by a judge (again for up to four weeks, a cycle that may continue for long periods). The police may release the pretrial detainee at any point when detainment is no longer necessary, which does not have to be approved by a judge.

Lengthy solitary confinement is common during pretrial detention in Denmark, with inmates locked in their cells up to 23 hours a day and one hour of fresh air, alone, each day (Andersen et al. 2003; Sestoft et al. 1998; Smith 2006). ${ }^{2}$ To avoid the risk of collusion (detainees aligning their testimonies), resocialization initiatives are offered only to the limited extent that these can be carried out in the private cell. Visitation is allowed but may often be restricted, and detention staff often monitor phone calls, visits, and communication. Although money bail systems do not exist in Denmark, pretrial detention periods are often lengthy; the median time from facing criminal charges to adjudication in Denmark is 64 days for pretrial detainees, whereas it is 112 days for released defendants. ${ }^{3}$ All told, about one in three incarcerated Danes is a pretrial detainee (Walmsley 2016a), and relatively few (about 16 percent) are charged with violent crimes (Danish Prison and Probation Service 2017). Finally, around 20 percent of pretrial detainment cases in Denmark fail to lead to a prison sentence (Smith and Jakobsen 2017).

\section{Data}

We exploit Danish register data for the analysis to follow. Using register data for research purposes has become increasingly common because of their accuracy, flexibility, and level of detail. In Denmark, tax records, contact with the criminal justice system, life events, and so on are linked to a unique personal identification number by the relevant agencies and reported to Statistics Denmark, the national statistical agency. Statistics Denmark documents the content of each variable, notes potential discontinuities in variables over time, and makes individual-level, deidentified data available to researchers for specific research questions. Data are available for the entire population and across years (most registers are available since 1980). In the context of our study, for example, we were able to establish exactly the relevant comparison groups for analyzing the association between pretrial detention and work, family attachment, and recidivism while taking the impact of conviction into account.

Comparison groups. We rely on three criminal justice registers to construct our comparison groups. From the incarcerations register we obtain all incarceration spells that were initiated and ended during 1995 to 2010 that included a period of pretrial detention. The incarcerations register holds information on all admissions and releases from correctional facilities in Denmark, including from pretrial detention centers, and exact dates differentiate between arrest, pretrial detention, and serving a sentence. From the charges register, we merge information on crime 
type (as per the charge) and offense date. From the convictions register, we obtain information on case outcomes. Here, a particularly important distinction is the one between whether the defendant was found guilty of the crime (by bargain or in court) or not (found not guilty or case dropped), as well as the sentencing outcome. These distinctions are important because they, in combination with the criminal justice registers, allow us to distinguish between five groups: (1) pretrial detainees who were not convicted; (2) pretrial detainees who were convicted and served the full sentence pretrial; (3) pretrial detainees who were convicted and then sentenced to additional imprisonment; (4) pretrial detainees who were convicted and then sentenced to other sanctions (primarily probation); and, last, (5) those who were convicted but never incarcerated; this group serves as the referent category. ${ }^{4}$ Our comparison groups thus employ a similar process of strategic comparison commonly employed in a number of prior works on the consequences of criminal justice contact for social life (e.g., Apel and Sweeten 2010; Porter and King 2015; Maroto and Sykes 2019; Western 2006). Using all incarceration spells with observations pre- and postincarceration in the registers yields 75,187 cases and represents 50,446 unique persons. Seventy-eight percent of people in the register data experienced one case, 95 percent had three or fewer spells, and a small minority experienced many cases over the course of the study period.

Outcome variables. We focus on three domains that could be affected by pretrial detention: labor market outcomes, family outcomes, and recidivism. We measure the outcome variables during the three years preceding admission and the three years following release.

Two variables measure labor market outcomes. The first measures monthly labor earnings, that is, earnings obtained from employment. We report earnings in 2010 Organisation for Economic Co-operation and Development (OECD) individual consumption purchasing power parity (PPP) adjusted U.S. dollars (USD) (i.e., the 2010 earnings in USD while taking fluctuations in local prices into account). The second denotes monthly employment, measured by a binary indicator of whether the person had any income from work during the month. Information on earnings come from tax records and includes all sources of legal income from work. The measure is annual, and we split the annual numbers by 12 to achieve average monthly earnings. Because we have precise incarceration and release dates, we can then note average monthly earnings prior to admission and following release. For years that precede or follow the year of the incarceration, we are certain that the earnings in fact either precede or follow incarceration. The same is true for incarceration spells that include January 1 . Spells initiated and terminated during the same year present a challenge regarding the timing of earnings relative to the timing of incarceration. Our solution is to count as preadmission earnings the number of preadmission months during that year and assign each of these months the average monthly earnings during the year. We do the same postrelease. As a consequence, our earnings measure is imprecise during a period up to \pm 11 months from admission and release. In the graphical material we present, we mark these months that are subject to imprecision and exclude these months from our statistical models. 
Two variables measure family outcomes. The first measures whether a person lives with a partner; the second measures whether a person lives together with his children. We construct these measures from the housing registers and demographic registers; living with a partner includes both marital and nonmarital relationships, and living with children measures whether one shares an address with one's own children. The housing register provides exact dates on when people move, allowing us to take move timing relative to incarceration timing into account.

Two variables measure recidivism. The first measures criminal conviction; the second measures arrest. Criminal conviction measures whether one is found guilty of violating the Penal Code during each of the three years preceding and following incarceration. Importantly, we use the charges register to obtain offense dates; we use timing of the offense rather than the timing of conviction (which may vary with court caseloads and the like). For arrests we exploit the details of the incarceration register to note whether a person was arrested during each of the three years preceding and following the incarceration in question. Importantly, we use case identifiers to ensure that our outcome measures of criminal conviction and arrest exclude contact with the criminal justice system that is recorded on the same case identifier as the case that selects them into the sample in the first place.

Background characteristics. Our analytic strategy does not strictly require control variables because it focuses on individual change. There are two reasons why we include a range of background characteristics, however. First, controlling for background characteristics increases the precision of our estimates by reducing the error term variance of our statistical model. Second, background characteristics allow us to describe how the people in our comparison groups differ, thus providing a better understanding of the social mechanisms that select people into each of the comparison groups.

From the demographic registers we add age at the time of the criminal charge, parental status, and ethnic minority background (in Denmark, this indicates that either the focal person or their parents immigrated from a non-Western country). From the educational register we add years of schooling (and a dummy variable indicating missing educational information for those who do not show up in the register). From the criminal justice registers we add number of previous convictions, number of incarceration experiences, and whether the current incarceration is a person's first, second, or third or more. We also add details of the current incarceration, namely, length of incarceration (in months), how often the detainee was transferred to another facility, and facility type (local arrest, low or high security, or other facilities). Last, we include crime type from the criminal charge: violent, property, or other crime.

Sample. From the criminal justice registers we select cases that include a period of pretrial detention of seven days or more. We use this cutoff because the shortest possible prison sentences in Denmark are seven days, and our analyses rely on comparing pretrial detainees who are found not guilty with pretrial detainees who end up serving their full sentence pretrial. Serving a full sentence pretrial is simply not possible for less than seven days. For the "convicted only" comparison group, we select cases resulting in conviction but with no incarceration (except arrest for less than 24 hours). We include only cases initiated and terminated within the 
1995 to 2010 window. We restrict our sample to include only men because only around five percent of prison sentences in Denmark are handed to women. Last, we focus only on those 18 to 59 years old at admission because pretrial detainees younger than 18 in Denmark are detained in secured youth custody-which differs substantially from the experience we are interested in analyzing (Bengtsson 2012).

\section{Method}

Our analyses proceed in several steps. First, we present descriptive results showing how our comparison groups differ prior to detention and following release, using labor market outcomes as a salient example. We then present descriptive statistics of the background variables by comparison group. The point is to show that substantial differences exist across the comparison groups even before incarceration. The preadmission differences come as little surprise as there are important mechanisms selecting specific men into each comparison group both in observed characteristics (which we show in the first analytical step) and in characteristics that are unobserved in the data.

Second, the descriptive differences across comparison groups highlight the importance of using an analytic approach that takes individual change in the outcomes into account rather than focusing only on postrelease differences: the focus on individual change allows us to factor in the differences (observed and unobserved time-invariant) between the comparison groups and provide unbiased average estimates (for as long as all selection into the comparison groups is random conditional on background characteristics and outcomes prior to detention, otherwise known as the conditional independence assumption). To estimate the average effect of pretrial detention on labor market outcomes, we model the change in individual outcomes as follows:

$$
\begin{gathered}
y_{i c t}=\alpha_{t} \\
+\beta_{t} \text { Pretrial }_{i c t} \\
+\gamma_{t}{\text { Pretrial } \times \text { Notconvicted }_{i c t}}+\delta_{t}{\text { Pretiral } \times \text { Prison }_{i c t}} \\
+\theta_{t}{\text { Pretrial } \times \text { Probation }_{i c t}} \\
+\pi \boldsymbol{X}_{i c}+\rho Y M_{i c}+\varepsilon_{i c t}
\end{gathered}
$$

Here, $y_{\text {ict }}$ denotes the outcome under study for individual $i$ prior to $(t=0)$ or following $(t=1)$ the case $(c)$ in question. The model is set up such that the intercept $(\alpha)$ measures the preadmission average for the relevant outcomes for the convicted only group when $t=0$ and measures the change in that outcome for that group from before to after conviction when $t=1$. Because all groups except the convicted only group experience pretrial detention, $\beta_{t=0}$ measures the preadmission difference in outcomes between the convicted only group and the group who serve their full sentence pretrial. Correspondingly, $\beta_{t=1}$ measures any changes from before to after incarceration for the latter group in addition to the change that the convicted only 
group experience. Because of the additive structure of the model, the parameters associated with the remaining pretrial detention groups measure the level difference $(t=0)$ and change $(t=1)$ for these groups in addition to what was just described for the group who serve the full sentence pretrial. For the Pretrial $\times$ Notconvicted group, for example, $\gamma_{t=0}$ measures any level difference before incarceration between those who serve their full sentence pretrial and those who are pretrial detained but not convicted. And $\gamma_{t=1}$ measures any change to the outcome from before to after detainment for the pretrial detained but not convicted group, which is added to the change experienced by those who serve their full sentence pretrial (and which is already measured relative to the change for the convicted only group). In this way, the model measures any additional effects of pretrial detention with and without conviction while taking the general trend from $t=0$ to $t=1$ for the convicted only group into account. For those who are sentenced to imprisonment or other sanctions in addition to experiencing pretrial detainment, $\delta$ and $\theta$ do the same. These last two comparison groups and corresponding parameters are mainly included in the model to provide a full picture of how the focal outcomes respond to different types of contact with the criminal justice system. $X$ is a vector of control variables (which we have already described under Background Characteristics), $Y M$ denotes year and month fixed effects to take general time trends into account, and $\varepsilon$ is the model's error term. We estimate the models using ordinary least squares. Last, to take into account the issue of persons occurring in the data more than once, we cluster our standard errors at the individual level (i.e., by personal identification numbers rather than person by case).

There are two fundamental identifying assumptions behind our first statistical model for measuring the effect of pretrial detention net of conviction. The first is one of common trends, and in our case, we rely on two common trend assumptions. First, we expect a general increase in labor market outcomes with age, and we therefore assume that the group of men who were convicted but not incarcerated can be said to express this general trend. Essentially, we assume that the other comparison groups would have experienced the same trend in outcomes had they not experienced any additional contact with the criminal justice system. Second, to tease out the consequences of pretrial detention with and without conviction, we assume that the trend in outcomes from before the criminal case to after pretrial detention expresses what the trend in outcomes would have been for the pretrial incarcerated but not convicted group if they had been convicted of the crime. We also compare the trends in outcomes for the last two comparison groups (sentenced to other sanctions and sentenced to additional postconviction imprisonment) with the one for those who served their full sentence pretrial, effectively allowing these trends to express any additional consequence that either imprisonment or other sanctions have over and above pretrial detention.

The second identifying assumption behind our statistical model concerns the exogeneity of the conviction decision, conditional on background characteristics and the common trends that were just laid out. We cannot rule out that differences between the comparison groups that are unobserved in the data but correlate with both conviction decision and outcomes may drive some of our results. When we talk about effects of pretrial detention with or without conviction, this important 
caveat must be kept in mind: we compare changes in outcome trends among these two groups of detainees who are comparable in terms of observed characteristics and precustody trends, yet other unobserved (e.g., time-variant) differences across the group may be driving some of the results. To assess whether the results from the models we just presented could be driven by such unobserved differences between the people in our data (or, to be specific, differences across people in how the dependence between any unobserved individual component and the observed covariates in the model pan out), we supplement our statistical model with an individual-level fixed effects specification. Here, we assign an intercept to each person in the data and then observe how the outcomes change as each month passes. Whereas the statistical model defined above compares the average outcome of an individual after release with the average outcome of the same individual before admission (i.e., two observations per person), we here exploit the full panel to have several observations per person (i.e., one observation per month per person per case). The fixed effect model thereby measures whether we observe a change in individual trajectories in the outcomes that corresponds with the timing of incarceration/conviction, measured relative to each individual's starting point and development in the outcome. ${ }^{5}$ Importantly, the individual fixed effects strategy does not rule out the possibility that unobserved and time-variant factors may still be driving our results for the "effect" of pretrial detention on outcomes. As such, whereas large differences between estimates from the individual fixed effects strategy and our main results would imply substantial risk that our main results could be biased, a lack of differences between the estimates is no guarantee of the opposite.

Third, we focus on people who had family attachment just prior to being taken into custody (i.e., people who were living with a partner and/or living with their children). We evaluate whether their risks of losing this family attachment differ following release depending on the type of contact with the criminal justice system that they experienced. We estimate Cox proportional hazard models to measure how the risks of losing family attachment depend on type of criminal justice contact while controlling for background characteristics. ${ }^{6}$

Fourth, we summarize the results from a number of robustness checks. These checks serve to show that our main results are general and hence not driven by any specific criminal offense type, facility type, or outcome measurement window.

\section{Results}

\section{Descriptive Statistics}

Figure 1 presents monthly average earnings (left) and the monthly share with labor earnings (right) up to 36 months before and after the case. Focusing on the period after the case, the group that experienced both pretrial detention and a sentenced term of imprisonment fares worst across both the amount of earnings and employment. Their employment rate is around 30 percent when released from prison, half that of the convicted only group. The convicted group that served their entire sentence pretrial follows the same pattern. Their outcomes following the 


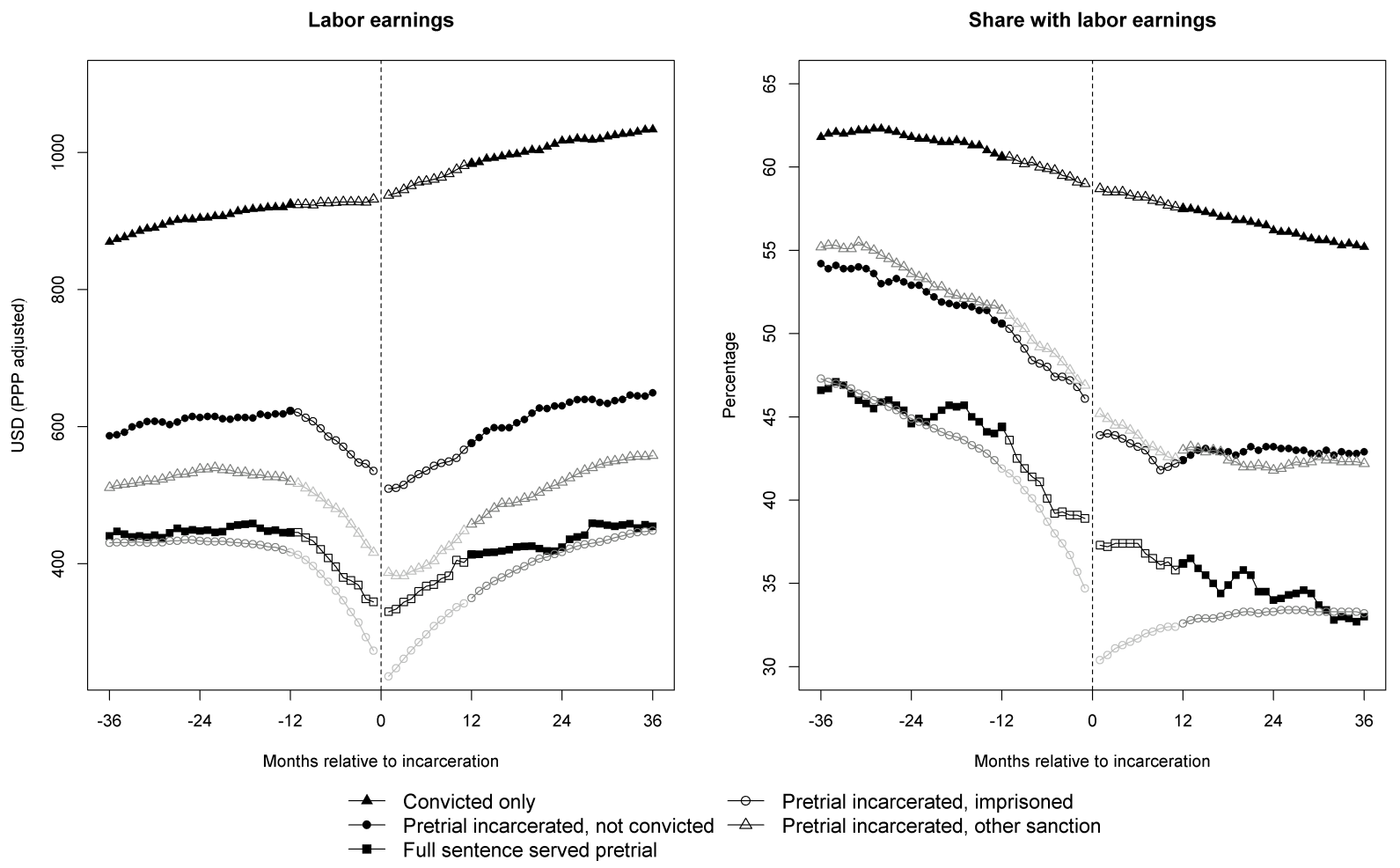

Figure 1: Labor market outcomes before and after incarceration or conviction. Men, Denmark, 1995 to 2010. $N=75,187$. Labor earnings measured in 2010 OECD individual consumption PPP adjusted USD. Labor earnings are uncertain during the last 11 months before admission/conviction and during the first 11 months following release/conviction because they are derived from annual labor earnings. In our estimation results we exclude these uncertain data points.

case are, however, slightly better, most likely because they are sentenced to shorter terms that do not exceed their period of pretrial detention. At the other extreme, those who are only convicted (but never incarcerated) fare the best across both labor market outcomes. In between these extremes fall two groups: those who are detained pretrial and then sentenced to other sanctions fare the same as those who are pretrial detained but not convicted. The latter result most likely reflects the highly select nature of this group; probationers, for example, differ from prisoners on many parameters as well.

It is evident from Figure 1, however, that large differences exist between the groups before the case in question. The sorting of groups in terms of the outcomes is similar to the postrelease pattern just described, underscoring how important it is to analyze individual change in outcomes rather than simply postrelease differences in a setup such as ours. Over the observation period, the average labor earnings increase for the convicted only group, and the earnings response to conviction is negligible (left), although there is a fairly strong downward slope to the share of these men who actually have income from work (right). For the other groups-the 
groups that experience pretrial detention-we observe a stronger labor market response. Pretrial detainees who are sentenced to imprisonment have the worst labor market outcomes, whether or not the full sentence is served pretrial or there is additional imprisonment following conviction. This finding makes sense, as people who are sentenced to imprisonment are generally worse off. Note the stronger discontinuity in the share with labor earnings (right) for those who are sentenced to additional imprisonment than for those who serve the full sentence pretrial, likely reflecting their longer absence from society. The developments in labor market outcomes for the group that is detained pretrial but not convicted and the group that is detained and sentenced to community sanctions are, again, fairly comparable. Both their monthly average earnings and the share with labor earnings in these groups fall in between the group that is only convicted and the two groups that are sentenced to imprisonment.

The differences just shown could simply reflect that the comparison groups are made up of vastly different men. We therefore compare means and standard deviations by comparison group across background characteristics in Table 1. Results support the claim that there are compositional differences between the groups. The groups of pretrial detainees who either are not convicted or end up having served their full sentence pretrial, for example, are much smaller than the other groups. As was also reflected in the outcomes, those who serve their full sentence pretrial, on average, resemble those who are detained pretrial and then sentenced to an additional term of imprisonment, except in highly predictable ways; the additional imprisonment group is of course incarcerated for longer, and they tend to experience more transfers between facilities because almost all men in the pretrial sentence only group serve their time in a local arrest facility.

The composition of the group that experiences pretrial detention but not conviction generally falls in between the composition of the convicted only group and the group that is detained pretrial and then sentenced to other sanctions. A few important exceptions stand out, however, perhaps indicating that the pretrial detained but not convicted group is to some degree made up of people with more criminal justice experience and comprises a larger share of ethnic minorities, echoing findings from a previous study showing ethnic disparities in groundless arrest and pretrial detention in Denmark (Holmberg and Kyvsgaard 2003).

The lower rows of Table 1 list the distributions of our outcome variables. Focusing on outcomes related to family life and criminal recidivism (labor market outcomes were described in detail in the figure above), it is evident that although there are differences between the comparison groups in these outcomes both prior to incarceration and following release, the "response" to the incarceration experience seems to be fairly similar across the groups. As such, we do not expect to find any notable consequences of pretrial detention on the change in these average outcomes from before incarceration to following release.

\section{Estimation Results}

Labor market outcomes. Table 2 presents the results from our statistical model that measures the change in labor market outcomes for the comparison groups. 
Table 1: Descriptive statistics of analytic sample, by sanction status. Men, Denmark, 1995 to 2010.

\begin{tabular}{|c|c|c|c|c|c|}
\hline & $\begin{array}{c}\text { Convicted } \\
\text { only }\end{array}$ & $\begin{array}{c}\text { Pretrial } \\
\text { incarcerated, } \\
\text { not } \\
\text { convicted }\end{array}$ & $\begin{array}{l}\text { Sentence } \\
\text { served } \\
\text { pretrial }\end{array}$ & $\begin{array}{c}\text { Pretrial } \\
\text { incarcerated, } \\
\text { then } \\
\text { imprisoned }\end{array}$ & $\begin{array}{c}\text { Pretrial } \\
\text { incarcerated, } \\
\text { then other } \\
\text { sanctions }\end{array}$ \\
\hline Age & $\begin{array}{c}34.500 \\
(11.510)\end{array}$ & $\begin{array}{l}29.626 \\
(9.089)\end{array}$ & $\begin{array}{l}30.335 \\
(8.668)\end{array}$ & $\begin{array}{l}29.606 \\
(8.306)\end{array}$ & $\begin{array}{l}29.330 \\
(9.287)\end{array}$ \\
\hline Parent & $\begin{array}{c}0.248 \\
(0.432)\end{array}$ & $\begin{array}{c}0.241 \\
(0.428)\end{array}$ & $\begin{array}{c}0.155 \\
(0.362)\end{array}$ & $\begin{array}{c}0.152 \\
(0.359)\end{array}$ & $\begin{array}{c}0.180 \\
(0.384)\end{array}$ \\
\hline Ethnic minority background & $\begin{array}{c}0.183 \\
(0.387)\end{array}$ & $\begin{array}{c}0.392 \\
(0.488)\end{array}$ & $\begin{array}{c}0.290 \\
(0.454)\end{array}$ & $\begin{array}{c}0.188 \\
(0.391)\end{array}$ & $\begin{array}{c}0.214 \\
(0.410)\end{array}$ \\
\hline 9 years schooling & $\begin{array}{c}0.354 \\
(0.478)\end{array}$ & $\begin{array}{c}0.430 \\
(0.495)\end{array}$ & $\begin{array}{c}0.475 \\
(0.500)\end{array}$ & $\begin{array}{c}0.529 \\
(0.499)\end{array}$ & $\begin{array}{c}0.452 \\
(0.498)\end{array}$ \\
\hline 10 years schooling & $\begin{array}{c}0.215 \\
(0.411)\end{array}$ & $\begin{array}{c}0.221 \\
(0.415)\end{array}$ & $\begin{array}{c}0.197 \\
(0.398)\end{array}$ & $\begin{array}{c}0.198 \\
(0.399)\end{array}$ & $\begin{array}{c}0.243 \\
(0.429)\end{array}$ \\
\hline 12 years schooling & $\begin{array}{c}0.100 \\
(0.300)\end{array}$ & $\begin{array}{c}0.075 \\
(0.264)\end{array}$ & $\begin{array}{c}0.053 \\
(0.224)\end{array}$ & $\begin{array}{c}0.045 \\
(0.207)\end{array}$ & $\begin{array}{c}0.068 \\
(0.251)\end{array}$ \\
\hline 13 years schooling & $\begin{array}{c}0.199 \\
(0.399)\end{array}$ & $\begin{array}{c}0.143 \\
(0.350)\end{array}$ & $\begin{array}{c}0.124 \\
(0.330)\end{array}$ & $\begin{array}{c}0.100 \\
(0.301)\end{array}$ & $\begin{array}{c}0.116 \\
(0.320)\end{array}$ \\
\hline 14 years schooling & $\begin{array}{c}0.022 \\
(0.146)\end{array}$ & $\begin{array}{c}0.016 \\
(0.124)\end{array}$ & $\begin{array}{c}0.008 \\
(0.088)\end{array}$ & $\begin{array}{c}0.008 \\
(0.090)\end{array}$ & $\begin{array}{c}0.013 \\
(0.113)\end{array}$ \\
\hline $15+$ years schooling & $\begin{array}{c}0.045 \\
(0.208)\end{array}$ & $\begin{array}{c}0.027 \\
(0.162)\end{array}$ & $\begin{array}{c}0.021 \\
(0.142)\end{array}$ & $\begin{array}{c}0.009 \\
(0.097)\end{array}$ & $\begin{array}{c}0.019 \\
(0.138)\end{array}$ \\
\hline Missing education & $\begin{array}{c}0.065 \\
(0.246)\end{array}$ & $\begin{array}{c}0.087 \\
(0.282)\end{array}$ & $\begin{array}{c}0.120 \\
(0.325)\end{array}$ & $\begin{array}{c}0.109 \\
(0.312)\end{array}$ & $\begin{array}{c}0.087 \\
(0.282)\end{array}$ \\
\hline Number of previous convictions & $\begin{array}{c}0.219 \\
(0.414)\end{array}$ & $\begin{array}{c}0.154 \\
(0.361)\end{array}$ & $\begin{array}{c}0.088 \\
(0.284)\end{array}$ & $\begin{array}{c}0.058 \\
(0.234)\end{array}$ & $\begin{array}{c}0.155 \\
(0.362)\end{array}$ \\
\hline Total number of incarcerations & $\begin{array}{l}1.358 \\
(0.893)\end{array}$ & $\begin{array}{c}2.398 \\
(2.526)\end{array}$ & $\begin{array}{c}3.831 \\
(4.684)\end{array}$ & $\begin{array}{c}4.157 \\
(4.587)\end{array}$ & $\begin{array}{c}2.353 \\
(2.764)\end{array}$ \\
\hline Current incarceration is first & $\begin{array}{c}0.877 \\
(0.329)\end{array}$ & $\begin{array}{c}0.645 \\
(0.478)\end{array}$ & $\begin{array}{c}0.554 \\
(0.497)\end{array}$ & $\begin{array}{c}0.520 \\
(0.500)\end{array}$ & $\begin{array}{c}0.763 \\
(0.425)\end{array}$ \\
\hline Current incarceration is second & $\begin{array}{c}0.090 \\
(0.286)\end{array}$ & $\begin{array}{c}0.206 \\
(0.404)\end{array}$ & $\begin{array}{c}0.178 \\
(0.383)\end{array}$ & $\begin{array}{c}0.186 \\
(0.389)\end{array}$ & $\begin{array}{c}0.119 \\
(0.324)\end{array}$ \\
\hline Current incarceration is third+ & $\begin{array}{c}0.034 \\
(0.180)\end{array}$ & $\begin{array}{c}0.149 \\
(0.356)\end{array}$ & $\begin{array}{c}0.268 \\
(0.443)\end{array}$ & $\begin{array}{c}0.295 \\
(0.456)\end{array}$ & $\begin{array}{c}0.118 \\
(0.322)\end{array}$ \\
\hline Length of incarceration (months) & - & $\begin{array}{c}1.699 \\
(2.949)\end{array}$ & $\begin{array}{c}2.104 \\
(2.526)\end{array}$ & $\begin{array}{c}9.358 \\
(10.522)\end{array}$ & $\begin{array}{c}4.526 \\
(11.932)\end{array}$ \\
\hline Number of transfers during incarceration & - & $\begin{array}{c}0.464 \\
(0.682)\end{array}$ & $\begin{array}{c}0.349 \\
(0.625)\end{array}$ & $\begin{array}{c}1.260 \\
(1.568)\end{array}$ & $\begin{array}{c}0.486 \\
(0.789)\end{array}$ \\
\hline Share in local arrest & - & $\begin{array}{c}0.973 \\
(0.134)\end{array}$ & $\begin{array}{c}0.987 \\
(0.101)\end{array}$ & $\begin{array}{c}0.671 \\
(0.369)\end{array}$ & $\begin{array}{c}0.857 \\
(0.284)\end{array}$ \\
\hline Share in high security facility & - & $\begin{array}{c}0.012 \\
(0.093)\end{array}$ & $\begin{array}{c}0.005 \\
(0.067)\end{array}$ & $\begin{array}{c}0.066 \\
(0.184)\end{array}$ & $\begin{array}{c}0.008 \\
(0.072)\end{array}$ \\
\hline Share in low security facility & - & $\begin{array}{c}0.001 \\
(0.021)\end{array}$ & $\begin{array}{c}0.000 \\
(0.000)\end{array}$ & $\begin{array}{c}0.251 \\
(0.358)\end{array}$ & $\begin{array}{c}0.001 \\
(0.036)\end{array}$ \\
\hline Share in other facility & - & $\begin{array}{c}0.014 \\
(0.096)\end{array}$ & $\begin{array}{c}0.008 \\
(0.076)\end{array}$ & $\begin{array}{c}0.000 \\
(0.000)\end{array}$ & $\begin{array}{c}0.133 \\
(0.275)\end{array}$ \\
\hline Charged with violent crime & $\begin{array}{c}0.385 \\
(0.487)\end{array}$ & $\begin{array}{c}0.323 \\
(0.468)\end{array}$ & $\begin{array}{c}0.362 \\
(0.481)\end{array}$ & $\begin{array}{c}0.254 \\
(0.435)\end{array}$ & $\begin{array}{c}0.198 \\
(0.398)\end{array}$ \\
\hline Charged with property crime & $\begin{array}{c}0.604 \\
(0.489)\end{array}$ & $\begin{array}{c}0.387 \\
(0.487)\end{array}$ & $\begin{array}{c}0.459 \\
(0.499)\end{array}$ & $\begin{array}{c}0.550 \\
(0.497)\end{array}$ & $\begin{array}{c}0.631 \\
(0.483)\end{array}$ \\
\hline Charged with other crime & $\begin{array}{c}0.011 \\
(0.106)\end{array}$ & $\begin{array}{c}0.290 \\
(0.454)\end{array}$ & $\begin{array}{c}0.179 \\
(0.384)\end{array}$ & $\begin{array}{c}0.195 \\
(0.396)\end{array}$ & $\begin{array}{c}0.172 \\
(0.377)\end{array}$ \\
\hline Average earnings before & $\begin{array}{c}909.359 \\
(1,137.413)\end{array}$ & $\begin{array}{c}599.793 \\
(893.087)\end{array}$ & $\begin{array}{c}431.698 \\
(726.309)\end{array}$ & $\begin{array}{r}406.877 \\
(732.61)\end{array}$ & $\begin{array}{c}510.908 \\
(837.719)\end{array}$ \\
\hline Average earnings after & $\begin{array}{c}994.932 \\
(1,218.274)\end{array}$ & $\begin{array}{c}596.422 \\
(925.345)\end{array}$ & $\begin{array}{c}414.076 \\
(761.011)\end{array}$ & $\begin{array}{c}375.948 \\
(742.183)\end{array}$ & $\begin{array}{c}483.358 \\
(864.285)\end{array}$ \\
\hline Share with earnings before & $\begin{array}{c}0.769 \\
(0.422)\end{array}$ & $\begin{array}{c}0.724 \\
(0.447)\end{array}$ & $\begin{array}{c}0.649 \\
(0.478)\end{array}$ & $\begin{array}{c}0.650 \\
(0.477)\end{array}$ & $\begin{array}{c}0.731 \\
(0.444)\end{array}$ \\
\hline Share with earnings after & $\begin{array}{c}0.716 \\
(0.451)\end{array}$ & $\begin{array}{c}0.625 \\
(0.484)\end{array}$ & $\begin{array}{c}0.555 \\
(0.497)\end{array}$ & $\begin{array}{c}0.526 \\
(0.499)\end{array}$ & $\begin{array}{c}0.637 \\
(0.481)\end{array}$ \\
\hline
\end{tabular}

Note: Values are means above standard deviations in parentheses. 
Table 1 continued

\begin{tabular}{|c|c|c|c|c|c|}
\hline & $\begin{array}{c}\text { Convicted } \\
\text { only }\end{array}$ & $\begin{array}{c}\text { Pretrial } \\
\text { incarcerated, } \\
\text { not } \\
\text { convicted }\end{array}$ & $\begin{array}{c}\text { Sentence } \\
\text { served } \\
\text { pretrial }\end{array}$ & $\begin{array}{c}\text { Pretrial } \\
\text { incarcerated, } \\
\text { then } \\
\text { imprisoned }\end{array}$ & $\begin{array}{c}\text { Pretrial } \\
\text { incarcerated, } \\
\text { then other } \\
\text { sanctions }\end{array}$ \\
\hline Lives with partner before & $\begin{array}{c}0.239 \\
(0.426)\end{array}$ & $\begin{array}{c}0.181 \\
(0.385)\end{array}$ & $\begin{array}{c}0.138 \\
(0.345)\end{array}$ & $\begin{array}{c}0.119 \\
(0.323)\end{array}$ & $\begin{array}{c}0.120 \\
(0.325)\end{array}$ \\
\hline Lives with partner after & $\begin{array}{c}0.236 \\
(0.425)\end{array}$ & $\begin{array}{c}0.191 \\
(0.393)\end{array}$ & $\begin{array}{c}0.136 \\
(0.343)\end{array}$ & $\begin{array}{c}0.114 \\
(0.318)\end{array}$ & $\begin{array}{c}0.119 \\
(0.323)\end{array}$ \\
\hline Lives with children before & $\begin{array}{c}0.232 \\
(0.422)\end{array}$ & $\begin{array}{c}0.178 \\
(0.383)\end{array}$ & $\begin{array}{c}0.134 \\
(0.341)\end{array}$ & $\begin{array}{c}0.127 \\
(0.332)\end{array}$ & $\begin{array}{c}0.127 \\
(0.333)\end{array}$ \\
\hline Lives with children after & $\begin{array}{c}0.230 \\
(0.421)\end{array}$ & $\begin{array}{c}0.197 \\
(0.398)\end{array}$ & $\begin{array}{c}0.142 \\
(0.349)\end{array}$ & $\begin{array}{c}0.123 \\
(0.328)\end{array}$ & $\begin{array}{c}0.126 \\
(0.332)\end{array}$ \\
\hline Conviction before & $\begin{array}{c}0.352 \\
(0.478)\end{array}$ & $\begin{array}{c}0.567 \\
(0.496)\end{array}$ & $\begin{array}{c}0.682 \\
(0.466)\end{array}$ & $\begin{array}{c}0.770 \\
(0.421)\end{array}$ & $\begin{array}{c}0.582 \\
(0.493)\end{array}$ \\
\hline Conviction after & $\begin{array}{c}0.327 \\
(0.469)\end{array}$ & $\begin{array}{c}0.536 \\
(0.499)\end{array}$ & $\begin{array}{c}0.633 \\
(0.482)\end{array}$ & $\begin{array}{c}0.670 \\
(0.470)\end{array}$ & $\begin{array}{c}0.489 \\
(0.500)\end{array}$ \\
\hline Arrest before & $\begin{array}{c}0.305 \\
(0.460)\end{array}$ & $\begin{array}{c}0.601 \\
(0.490)\end{array}$ & $\begin{array}{c}0.698 \\
(0.459)\end{array}$ & $\begin{array}{c}0.772 \\
(0.420)\end{array}$ & $\begin{array}{c}0.589 \\
(0.492)\end{array}$ \\
\hline Arrest after & $\begin{array}{c}0.238 \\
(0.426)\end{array}$ & $\begin{array}{c}0.527 \\
(0.499)\end{array}$ & $\begin{array}{c}0.623 \\
(0.485)\end{array}$ & $\begin{array}{c}0.655 \\
(0.475)\end{array}$ & $\begin{array}{c}0.482 \\
(0.500)\end{array}$ \\
\hline$N$ & 27,376 & 2,797 & 1,017 & 38,990 & 5,007 \\
\hline
\end{tabular}

Note: Values are means above standard deviations in parentheses.

For each of the two labor market outcomes, the first model (1 and 4) reports raw correlations, that is, models without control variables. The second model ( 2 and 5) controls for background characteristics and time fixed effects, whereas the last model (3 and 6) reports results from models that include individual-level fixed effects (hence the larger number of observations). Focusing on the raw correlations before admission and only on labor market earnings, the groups that will become detained pretrial have lower average earnings, more than USD 450 lower per month relative to USD 900 for the convicted only group. Because of the structure of the model, this preadmission-level difference pertains only to the group that serves their full sentence pretrial. Those who experience additional imprisonment have USD 17 less per month, but this amount does not differ statistically from the USD -450 among those who serve the full sentence pretrial. Those who experience other sanctions have higher predetention earnings, almost USD 100 per month. The pretrial detainees who are not convicted have even higher average preadmission earnings than those who serve their full sentence pretrial, USD 160 more per month.

Following release, we observe an increase of USD 110 to average monthly earnings for the convicted only group. We also observe that this increase is not found for pretrial detainees: the additional change to their average labor earnings is around USD -120, effectively their earnings trajectories are flat across the case. The lack of either statistically significant or substantially important point estimates for any of the other pretrial detention groups indicates that pretrial detainees have uniformly lower average labor earnings-conviction and sentence status notwithstanding - at least in these uncontrolled models.

The differences between the comparison groups decrease, however, when we control for background characteristics and time fixed effects in model 2. Yet still, the overall conclusion remains the same, namely, that pretrial detainment effectively 
Table 2: Results from estimations of the change in labor market outcomes by pretrial detention status.

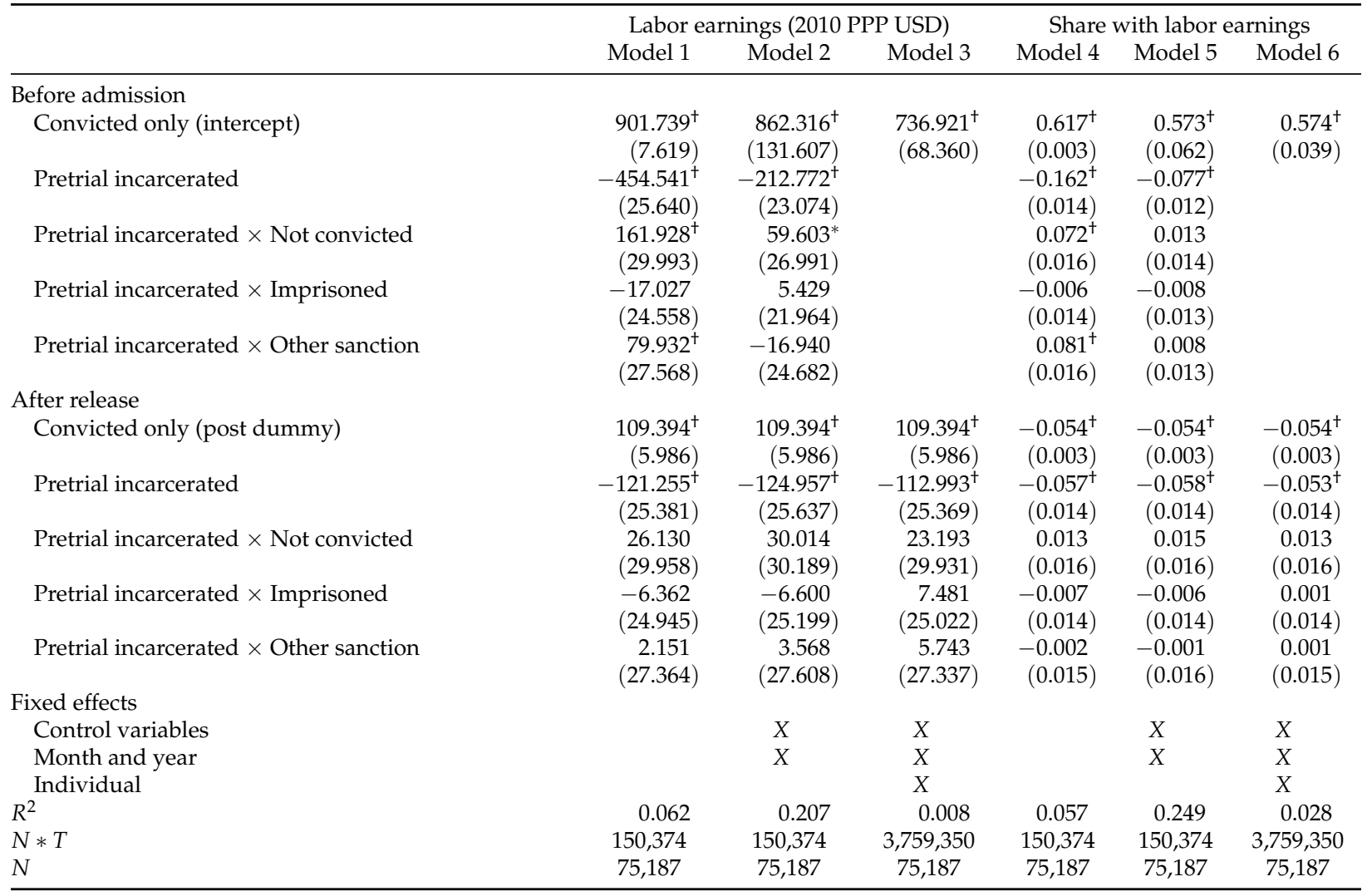

Note: Standard errors in parentheses are clustered at the individual level. $+p<0.01 ; * p<0.05$.

cancels the earnings trajectory from before to after incarceration that the detainees would, as per the model and thus as expressed by the convicted only group, have experienced if they had not been detained pretrial. We find this result no matter whether pretrial detainees are convicted or experience additional sentencing, such as imprisonment or other sanctions.

When we exploit the full extent of the data panel structure to include individuallevel fixed effects in model 3, we again arrive at the same conclusion. In this model, which cannot include preadmission average earnings of the comparison groups because they are differenced out by the fixed effects estimator (as mentioned and why several table entries are missing for this model), the intercept refers to the mean of the heterogeneity in labor earnings across all people in the data before admission. More importantly, the point estimates for postrelease labor earnings do not differ much from those reported in the first two columns of the table, suggesting that those results are not driven by individual heterogeneity. Turning to the share with labor earnings, our measure of labor market attachment, much the same conclusion arises (models 4 to 6 in Table 2). There are large differences in labor market attachment prior to admission, even though pretrial detainees who are not convicted or who are sentenced to other sanctions have better attachment than the ones who are sentenced to imprisonment. Following release, we observe a general decline in 
labor market attachment, and the share with labor earnings among the convicted only group drops by more than five percentage points. Pretrial detention doubles this loss, however, adding a six percentage point drop to labor market attachment. Again, it is pretrial detention per se and not conviction or sentence status that promotes this drop (the estimates related to the other pretrial detention groups are insignificant, both when we focus on raw correlations, when we control for background characteristics and time effects, and when we add individual fixed effects). Once again, adding individual fixed effects to the model does not alter the conclusions.

Family outcomes. We find no effects of pretrial detention on family outcomes for the full sample using the modeling strategy just presented (results presented in Table A.1 of the online supplement). ${ }^{7}$ When we observed large postrelease differences between the comparison groups on family outcomes (see Table 1 and Table A.1 of the online supplement), this finding was thus driven (almost) exclusively by preexisting differences between the men in those groups. It may be that family members respond to detention of loved ones differently than employers. The lack of an effect of pretrial detention (with or without conviction) on family outcomes could also mask a great deal of instability in family relations. If, for example, the men in our sample transition in and out of families, the steady average rates could reflect that as some of the men in our sample move out of relationships, others move into relationships, and so on.

Table 3 investigates this possibility and presents results from Cox proportional hazards models. We estimate the risk of transitioning out of a household family attachment with a partner or child, by comparison group. The advantage of using this model is that it allows us to control for background characteristics and time fixed effects, thereby somewhat corresponding to our main results. Results in Table 3 thus remove the differences between the groups that are driven by the composition of the groups on observed characteristics and by general time trends. We allow for the groups to differ in how their risk of transitioning out of families changes after release, to observe any heterogenous effects. Results are presented as hazard ratios indicating how much higher (hazard ratio larger than one) or lower (hazard ratio between zero and one) the risk of losing family attachment is for each group relative to the convicted only group.

Three years after release, around 70 percent of the convicted only group still live with the partner they did before conviction, and 65 percent who lived with their children at conviction still did so three years afterward. Pretrial detainees have higher risks of losing a family attachment (with one exception: the risk of losing coresidence with a partner is higher, but not statistically significantly so, for men who serve their full sentence pretrial when compared with the convicted only group). The rank of the risks generally corresponds to what one would expect and our findings for labor market outcomes. Those who are detained pretrial but not convicted have higher risks of losing both types of family attachment (1.29 and 1.25 times higher risks). Their risks are, however, lower than the groups that in addition to pretrial detention experience conviction and an additional sentence. The risks are especially stark among those who are sentenced to additional prison terms, an almost doubling of the risks. 
Table 3: Results from Cox proportional hazards models analyzing the risk of moving away from partner or children after release among those living with a partner or their children at admission. Men, Denmark, 1995 to 2010 .

\begin{tabular}{|c|c|c|}
\hline & $\begin{array}{c}\text { Moving away from partner } \\
\text { Hazard ratio }\end{array}$ & $\begin{array}{c}\text { Moving away from children } \\
\text { Hazard ratio }\end{array}$ \\
\hline \multicolumn{3}{|l|}{ Main effects } \\
\hline Convicted only & (reference) & (reference) \\
\hline Pretrial incarcerated, not convicted & $\begin{array}{l}1.292^{\dagger} \\
(0.120)\end{array}$ & $\begin{array}{l}1.250^{*} \\
(0.122)\end{array}$ \\
\hline Sentence served pretrial & $\begin{array}{l}1.098 \\
(0.211)\end{array}$ & $\begin{array}{l}1.601^{*} \\
(0.303)\end{array}$ \\
\hline Pretrial incarcerated then imprisoned & $\begin{array}{l}2.146^{\dagger} \\
(0.101)\end{array}$ & $\begin{array}{l}1.711^{\dagger} \\
(0.085)\end{array}$ \\
\hline Pretrial incarcerated then other sanction & $\begin{array}{l}1.695^{+} \\
(0.137)\end{array}$ & $\begin{array}{l}1.473^{\dagger} \\
(0.133)\end{array}$ \\
\hline \multicolumn{3}{|l|}{ Time-varying effects } \\
\hline Convicted only & (reference) & (reference) \\
\hline Pretrial incarcerated, not convicted & $\begin{array}{c}1.054 \\
(0.278)\end{array}$ & $\begin{array}{l}2.022^{+} \\
(0.388)\end{array}$ \\
\hline Sentence served pretrial & $\begin{array}{l}1.381 \\
(0.655)\end{array}$ & $\begin{array}{l}1.644 \\
(0.638)\end{array}$ \\
\hline Pretrial incarcerated then imprisoned & $\begin{array}{l}3.084^{\dagger} \\
(0.294)\end{array}$ & $\begin{array}{l}4.692^{+} \\
(0.424)\end{array}$ \\
\hline Pretrial incarcerated then other sanction & $\begin{array}{l}1.140 \\
(0.250)\end{array}$ & $\begin{array}{l}2.615^{\dagger} \\
(0.428)\end{array}$ \\
\hline \multicolumn{3}{|l|}{ Fixed effects } \\
\hline Control variables & $X$ & $X$ \\
\hline Month and year & $X$ & X \\
\hline Pseudo $R^{2}$ & 0.027 & 0.032 \\
\hline Total time-at-risk & 212,499 & 196,208 \\
\hline$N$ & 8,631 & 8,280 \\
\hline
\end{tabular}

Recidivism. Table 4 presents results for recidivism. Except for a general decrease in conviction ( 2.5 percentage points) and arrest (almost seven percentage points) from before to after incarceration-and uniformly lower rates for the imprisonment group following release (perhaps driven by age and deterrence; this group was incarcerated for longer than the other groups) - almost all parameter estimates following release are small and statistically insignificant. Importantly, these results suggest that the costs to labor market and family attachments for pretrial detainees are associated with no counterbalancing payoff in lower recidivism rates.

Robustness checks. We investigated whether our findings are driven by differences in other characteristics that affect criminal justice contact and/or social outcomes. In Section B of the online supplement, we detail the robustness analyses and provide results using the same or similar modeling technique presented above. Specifically, we analyze whether our results are robust across length of detention and time period; whether effects are stronger or weaker for first-time detainees; whether results differ geographically; and whether the main results are driven by the longest detention spells. In all cases, although the magnitude of the estimated effects may 
Table 4: Results from estimations of the change in criminal justice outcomes by pretrial detention status.

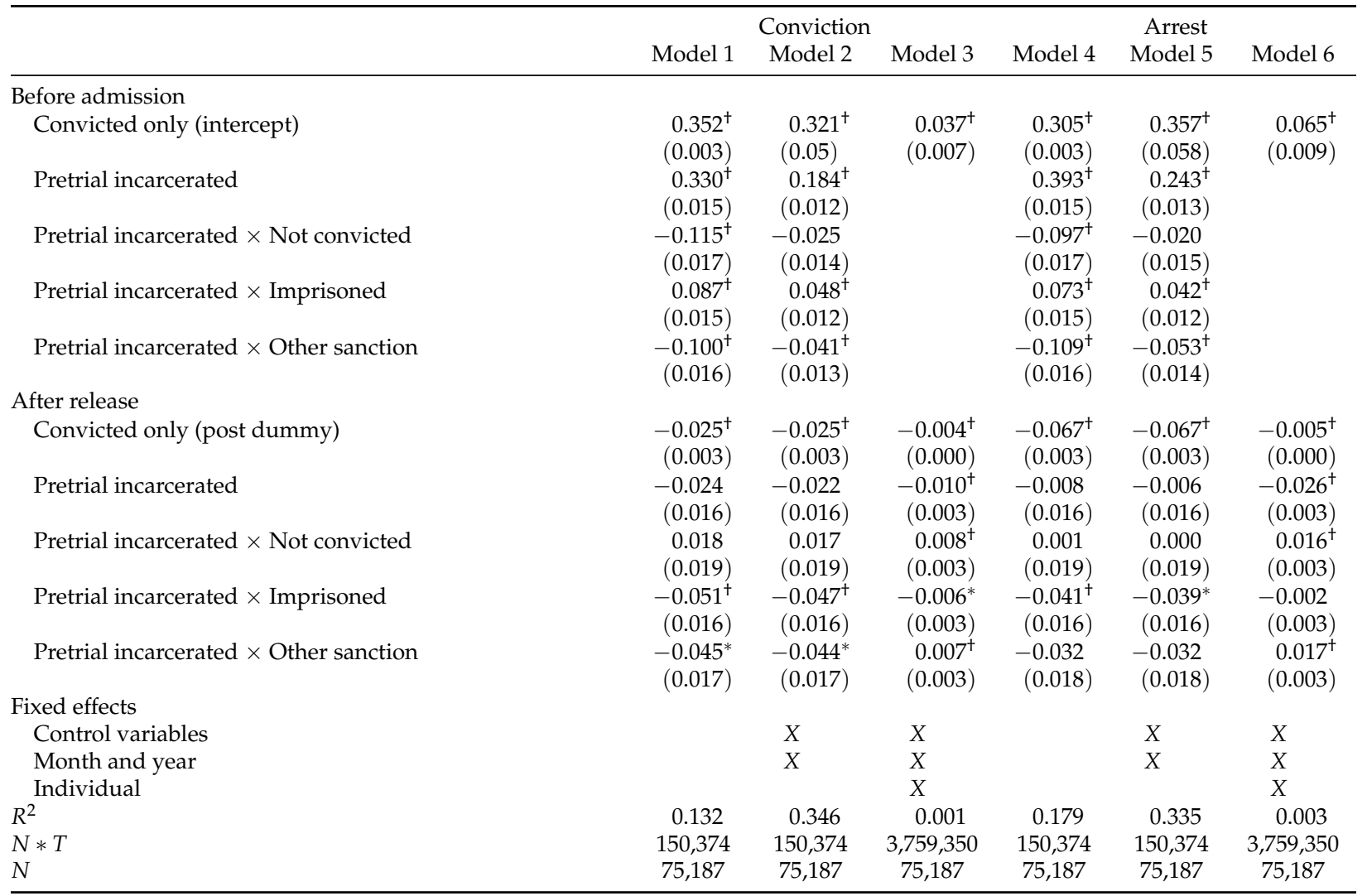

Note: Standard errors in parentheses are clustered at the individual level. $+p<0.01 ; * p<0.05$.

change slightly, the pattern of effects remains unchanged. Taken together, our results are robust across a variety of specifications and sample restrictions and indicate a clear disadvantaging penalty of pretrial detention, no matter whether one is found guilty of the crime in question or not. In addition to these robustness checks, we analyze whether our main results for labor market outcomes are sensitive to the choice of pre- and postdetention measurement points. The logic of this sensitivity analysis and the results concern the credibility of our identifying assumption of common trends and are described in Section $C$ of the online supplement. Results uniformly lend support to our main results, which thus are unlikely to be caused by our choice of pre- and postdetention measurement points.

\section{Discussion and Conclusion}

Our article makes three main contributions to the growing literature on the social consequences of criminal justice expansion. First, we show that pretrial detention, with or without conviction, imposes unique social costs for labor market and family attachments. This study suggests that pretrial detention should be added to the rapidly accumulating list of inefficiencies and hidden harms already associated 
with imprisonment in many Western democracies (Barker 2013; Comfort 2007; Kirk and Wakefield 2018; Pettit 2012; Turney and Connor 2019; Wildeman and Muller 2012).

Second, prior work makes it difficult to differentiate harms that flow from separation (e.g., incarceration) and those that flow from the imposition of a stigmatizing credential (e.g., a felony conviction or criminal record). With regard to separation, incarceration terms need not be lengthy to cause significant instabilities in employment and family life (Apel 2016; Comfort 2016). Similarly, although much research is focused on the imposition of a felony conviction (e.g., Manza and Uggen 2006; Pager 2003), stigmatizing labels conferred by the criminal justice system need not involve serious crimes (Kohler-Hausmann 2013), and even inaccurate digital records cause lasting harm (Lageson 2020). Given the nature of Danish register data, we are able to distinguish here between social costs that derive from detention and conviction, finding that pretrial detention imposes a unique cost for individuals. An important contextual difference is also relevant to this point; although a great deal of commentary is currently focused on privacy with respect to the dissemination of criminal records in the United States and Europe (Corda and Lageson 2019; Jacobs 2015; Lageson 2020), criminal records are not widely available to the general public in Denmark. Although we cannot definitively describe the mechanisms behind our results, this context constraint suggests they are driven directly by the detainment experience and separation from work and family, rather than by the stigma imposed by a criminal conviction or the dissemination of criminal records online.

Third, pretrial detention is at least partially motivated by an assessment that defendants present a danger to the public or a flight risk prior to adjudicationthis is formally the case in Denmark where prosecutors must identify a specific risk related to a specific charged defendant-but such determinations are not counterbalanced by evidence on the potential harms of detention for employment and family life. Our results show that detention results in consequential harms to labor market and family attachments that are, importantly, not counterbalanced by reductions in recidivism. Such results, taken together, raise serious questions about the (over)use of pretrial detention, where the pains of punishment are visited on those who may never be convicted of anything.

Although research on mass incarceration in Western democracies has tended to focus on postconviction imprisonment, this gap in research largely reflects the limited availability of data suited for analyzing pretrial and jail detention (Kirk and Wakefield 2018; Turney and Connor 2019). For this article, we used administrative data from Denmark to overcome the data challenge, an approach that offers both strengths and limitations. Strengths of registry data include full population information with precise and repeated measures of criminal justice contact and a wide array of background characteristics and outcomes; these attributes are difficult to find in other data sources. In U.S.-based surveys, for example, researchers must often infer pretrial detention when an incarcerated respondent does not report a conviction or rely on chance overlap between the timing of interviews and a respondent currently being held in detainment. In administrative data sets, pretrial detention is measured more cleanly but limited to a small set of jurisdictions or a limited set of outcomes (often employment- or criminal justice-related). Finally, it 
is difficult to glean any information on how many pretrial detainees there are or the conditions under which they are held in a number of countries (Walmsley 2016a).

There are, however, two main limitations of these data. The first concerns potential endogeneity among pretrial detainees who served their full sentence pretrial and those who were not convicted. Our statistical models assume that this decision is random, conditional on background characteristics and outcomes measured prior to detention. Although our results document common trends among these groups in the outcomes before detention, this assumption is fundamentally untestable. As such, whereas our results offer important knowledge on the consequences of system overreach in the form of pretrial detention, they are fundamentally descriptive.

The second limitation concerns generalizability: there are many differences between Denmark and other places in the use of pretrial detention. We noted elsewhere that the United States represents a criminal justice extreme and is thus the focus of much research attention; yet although average pretrial detention periods are similar between Denmark and the United States, the comparatively short prison sentences in Denmark allowed an analysis distinguishing pretrial detention from conviction, but prison terms in the United States are much longer and detention conditions in Denmark are arguably harsher relative to other countries. Moreover, the operation of criminal justice systems in many European countries is centralized, so there is less variability across regions within a particular country. In contrast, the diffuse nature of criminal justice processing in the United States, where county jails, state prisons, and federal prisons vary widely, or in countries where pretrial detainees are held in local police facilities present significant challenges. It is thus difficult to imagine a similar analysis-across many jurisdictions and outcomes-in a number of countries. We sacrifice generalizability to other contexts in order to provide clean measures of incarceration and conviction status while offering results on a variety of outcomes not often found together in other data sources.

With these caveats in mind, our work underscores the importance of considering new and hidden forms of criminal justice contact. Pretrial detention constitutes a substantial portion of all incarcerations throughout the world and represents a unique criminal justice experience. Pretrial detention is especially important because it imposes the pains of incarceration and consequences for social life on those who may never receive a legally imposed criminal label. From a systemic point of view, pretrial detention is thought to protect the public from potentially dangerous people during the adjudication process and ensures that defendants appear for trial. Yet whereas these aims may be noble, pretrial detention also represents a fundamental and - as results from Denmark in this article have shownconsequential denial of liberty, especially in cases with no corresponding finding of criminal responsibility to justify its use. In an era replete with examples of criminal justice system overreach and a web of entanglements between the criminal justice system and other institutions (e.g., Beckett 2018), it is nonetheless the individual and his family who must bear the consequences. As we have shown here, such consequences are clear well into the future and across two domains-work and family - that are central to social life. 


\section{Notes}

1 Dobbie et al. (2018) find that "the leave-out leniency measure [of bail judges] is highly predictive of detention decisions, but uncorrelated with case and defendant characteristics" (P. 203), suggesting critics of pretrial detention are correct when they note little relationship between detention decisions and risks to the public.

2 To break away from these solitary conditions of pretrial detention, there has been a recent development in Denmark to increase pretrial detainees' possibilities of visiting each other in their private cells.

3 Own calculation based on data from Statistics Denmark. Specifically, the median time from charge to adjudication in Denmark is found for cases with conviction of violating the Penal Code during 1995 to 2010.

4 Those who were convicted of a crime but who were not incarcerated are a random sample (drawn from the population of only convicted offenders) to reflect the distribution of offenses across time among those who experienced pretrial detention.

5 This specification also implies that we cannot control for time-invariant factors-which in this context cover background characteristics and other time constant variables such as dummies for group membership prior to admission-as the effects of these factors are soaked up by the individual fixed effects.

6 The Cox proportional hazards model relies on the basic assumption of proportionality in the hazard rates between the groups over the follow-up period. We test this assumption by regressing the scaled Schoenfeld residuals from the regressions on the time variable to observe whether the corresponding slope coefficient is zero. After allowing the impact of time from release to vary for age, being charged of property crime, and total number of incarcerations a person has experienced, we cannot reject this null hypothesis.

7 We also re-estimated these models with a truncated age distribution of men, ages 18 to 30. Results are substantively similar, although the younger men have lower levels of family attachment following release than was observed in the full sample (results available from the authors on request).

\section{References}

Andersen, Henrik Steen, D. Sestoft, T. Lillebaek, G. Gabrielsen, and R. Hemmingsen. 2003. "A Longitudinal Study of Prisoners on Remand: Repeated Measures of Psychopathology in the Initial Phase of Solitary versus Nonsolitary Confinement." International Journal of Law and Psychiatry 26:165-77. https://doi .org/10.1016/S0160-2527 (03)00015-3

Andersen, Signe Hald. 2015. "Serving Time or Serving the Community? Exploiting a Policy Reform to Assess the Causal Effects of Community Service on Income, Social Benefit Dependency, and Recivism." Journal of Quantitative Criminology 31(4):537-63. https://doi.org/10.1007/s10940-014-9237-2

Apel, Robert. 2016. "The Effects of Jail and Prison Confinement on Cohabitation and Marriage." Annals of the American Academy of Political and Social Science 665(1):103-26. https://doi.org/10.1177/0002716216629360

Apel, Robert, and Gary Sweeten. 2010. “The Impact of Incarceration on Employment during the Transition to Adulthood." Social Problems 57(3):448-79. https ://doi .org/10.1525/ sp. 2010.57 .3 .448 
Appleman, Laura I. 2012. "Justice in the Shadowlands: Pretrial Detention, Punishment, \& the Sixth Amendment." Washington and Lee Law Review 69(3):1297-369. https : //doi .org/ $10.2139 /$ ssrn. 2031196

Barker, Vanessa. 2013. "Nordic Exceptionalism Revisited: Explaining the Paradox of a Janus-Faced Regime." Theoretical Criminology 17(1):5-25. https://doi.org/10.1177/ 1362480612468935

Beckett, Katherine. 2018. "The Politics, Prospects, and Perils of Criminal Justice Reform in an Era of Mass Incarceration." Annual Review of Criminology 1:235-59. https://doi . org/10 . 1146/annurev-criminol-032317-092458

Bengtsson, Tea Torbenfeldt. 2012. "Boredom and Action: Experiences from Youth Containment." Journal of Contemporary Ethnography 41(5):526-53. https : //doi .org/10.1177/ 0891241612449356

Brame, Robert, Michael G. Turner, Raymond Paternoster, and Shawn D. Bushway. 2011. "Cumulative Prevalence of Arrest from Ages 8 to 23 in a National Sample." Pediatrics 129(1):21-27. https: //doi.org/10.1542/peds . 2010-3710

Comfort, Megan. 2007. "Punishment beyond the Legal Offender." Annual Review of Law and Social Science 3(1):271-84. https://doi.org/10.1146/annurev.lawsocsci.3. 081806. 112829

Comfort, Megan. 2016. “A Twenty-Four Hour a Day Job: The Impact of Frequent Low-Level Criminal Justice Involvement on Family Life." Annals of the American Academy of Political and Social Science 665(1):63-79. https ://doi .org/10.1177/0002716215625038

Corda, Alessandro, and Sarah E. Lageson. 2019. “Disordered Punishment: Workaround Technologies of Criminal Records Disclosure and the Rise of the New Penal Entrepreneurialism." British Journal of Criminology 60(2):245-64. https: //doi . org/10 . 1093/bjc/azz039

Danish Prison and Probation Service. 2017. Statistik 2016. Copenhagen: Danish Prison and Probation Service.

Demuth, Stephen. 2003. "Racial and Ethnic Differences in Pretrial Release Decision and Outcomes: A Comparison of Hispanic, Black, and White Felony Arrestees." Criminology 41(3):873-908. https ://doi.org/10.1111/j.1745-9125.2003.tb01007.x

Dobbie, Will, Jacob Goldin, and Crystal S. Yang. 2018. "The Effects of Pre-trial Detention on Conviction, Future Crime, and Employment: Evidence from Randomly Assigned Judges." American Economic Review 108(2):201-40. https://doi .org/10.1257/aer . 20161503

Fallesen, Peter, and Lars H. Andersen. 2017. "Explaining the Consequences of Imprisonment for Union Formation and Dissolution in Denmark." Journal of Policy Analysis and Management 36(1):154-77. https://doi.org/10.1002/pam.21933

Goldkamp, John S. 1983. “Questioning the Practice of Pretrial Detention: Some Empirical Evidence." Journal of Criminal Law and Criminology 74(4):1556-88. https : //doi . org/10 . $2307 / 1143065$

Gupta, Arpit, Christopher Hansman, and Ethan Frenchman. 2016. "The Heavy Costs of High Bail: Evidence from Judge Randomization." Journal of Legal Studies 45(2):471-505. https://doi.org/10.1086/688907

Haney, Craig, Joanna Weill, Shirin Bakhshay, and Tiffany Lockett. 2015. “Examining Jail Isolation: What We Don't Know Can Be Profoundly Harmful." Prison Journal 96(1):126-52. https://doi.org/10.1177/0032885515605491

Harding, David J., Jeffrey D. Morenoff, Anh P. Nguyen, and Shawn D. Bushway. 2018. "Imprisonment and Labor Market Outcomes: Evidence from a National Experiment." American Journal of Sociology 124(1):49-110. https : //doi .org/10.1086/697507 
Heard, Catherine, and Helen Fair. 2019. Pre-Trial Detention and Its Over-Use: Evidence from Ten Countries. University of London. https://prisonstudies.org/sites/default/files/ resources/downloads/pre-trial_detention_final.pdf

Heaton, Paul, Sandra Mayson, and Megan T. Stevenson. 2017. “The Downstream Consequences of Misdemeanor Pretrial Detention." Stanford Law Review 69:711. https: //doi.org/10.2139/ssrn. 2809840

Holmberg, Lars, and Kyvsgaard, Britta. 2003. "Are Immigrants and Their Descendants Discriminated against in the Danish Criminal Justice System?" Journal of Scandinavian Studies in Criminology \& Crime Prevention 4(2):125-42. https : //doi .org/10.1080/ 14043850310020027

Hood, Katherine, and Daniel Schneider. 2019. "Bail and Pretrial Detention: Contours and Causes of Temporal and County Variation." RSF: The Russell Sage Foundation Journal of the Social Sciences 5(1):126-49. https://doi .org/10.7758/rsf .2019.5.1.06

Jacobs, James B. 2015. The Eternal Criminal Record. Cambridge, MA: Harvard University Press. https://doi.org/10.4159/harvard.9780674735842

Kirk, David S., and Sara Wakefield. 2018. "Collateral Consequences of Punishment: A Critical Review and Path Forward." Annual Review of Criminology 1:171-94. https: //doi.org/10.1146/annurev-criminol-032317-092045

Kohler-Hausmann, Issa. 2013. "Misdemeanor Justice: Control without Conviction." American Journal of Sociology 119(2):351-93. https : //doi . org/10.1086/674743

Lageson, Sarah Esther. 2020. Digital Punishment: Privacy, Stigma, and the Harms of Data-Driven Criminal Justice. New York: Oxford University Press. https://doi.org/10.1093/oso/ 9780190872007.001 .0001

Loeffler, Charles E. 2013. “Does Imprisonment Alter the Life Course? Evidence on Crime and Employment from a Natural Experiment." Criminology 51(1):137-66. https://doi . org/10.1111/1745-9125.12000

Lowenkamp, Christopher T., Marie VanNostrand, and Alexander Holsinger. 2013. The Hidden Costs of Pretrial Detention. Houston, TX: Laura and John Arnold Foundation.

Manza, Jeff, and Christopher Uggen. 2006. Locked Out: Felon Disenfranchisement and American Democracy. New York: Oxford University Press. https://doi.org/10.1093/acprof : oso/9780195149326.001.0001

Maroto, Michelle, and Bryan L. Sykes. 2019. "The Varying Effects of Incarceration, Conviction, and Arrest on Wealth Outcomes in Young Adulthood." Social Problems 23:1-21. https : //doi.org/10.1093/socpro/spz023

Massoglia, Michael, Brianna Remster, and Ryan D. King. 2011. "Stigma or Separation? Understanding the Incarceration-Divorce Relationship." Social Forces 90(1):133-55. https : //doi.org/10.1093/sf/90.1.133

May, David C., Brandon K. Applegate, Rick Ruddell, and Peter B. Wood. 2014. “Going to Jail Sucks (and It Really Doesn't Matter Who You Ask)." American Journal of Criminal Justice 39(2):250-66. https://doi.org/10.1007/s12103-013-9215-5

Menefee, Michael R. 2018. "The Role of Bail and Pretrial Detention in the Reproduction of Inequality." Sociology Compass 12:1-9. https ://doi .org/10.1111/soc4.12576

Mitchell, John N. 1969. "Bail Reform and the Constitutionality of Pretrial Detention." Virginia Law Review 55(7):1223-42. https : //doi .org/10.2307/1071765

Pager, Devah. 2003. "The Mark of a Criminal Record." American Journal of Sociology 108(5):93775. https://doi.org/10.1086/374403 
Pettit, Becky. 2012. Invisible Men: Mass Incarceration and the Myth of Black Progress. New York: Russell Sage Foundation.

Porter, Lauren C., and Ryan D. King. 2015. "Absent Fathers or Absent Variables? A New Look at Parental Incarceration and Delinquency." Journal of Research in Crime and Delinquency 52(3):414-43. https : //doi.org/10.1177/0022427814552080

Ramakers, Anke, Robert Apel, Paul Nieubeerta, Anja Dirkzwager, and Johan Van Wilsem. 2014. "Imprisonment Length and Post-prison Employment Prospects." Criminology 52(3):499-527. https : //doi .org/10.1111/1745-9125.12042

Rankin, Anne. 1964. “The Effect of Pretrial Detention." New York University Law Review 39:641-55.

Rizer, Arthur, and Tracey Meares. 2020. "The 'Radical' Notion of the Presumption of Innocence." Executive Session on the Future of Justice Policy. New York: The Square One Project.

Schlesinger, Traci. 2005. "Racial and Ethnic Disparity in Pretrial Criminal Processing." Justice Quarterly 22(2):170-192. https://doi.org/10.1080/07418820500088929

Sestoft, Dorte Maria, Henrik Steen Andersen, Tommy Lillebaek, and Gorm Gabrielsen. 1998. "Impact of Solitary Confinement on Hospitalization among Danish Prisoners in Custody." International Journal of Law and Psychiatry 21(1):99-108. https : //doi . org/10 . 1016/S0160-2527 (97)00025-3

Scott-Hayward, Christine S., and Sarah Ottone. 2018. "Punishing Poverty: California's Unconstitutional Bail System." Stanford Law Review 70:167-78.

Scott-Hayward, Christine S., and Henry F. Fradella. 2019. “The Impact of Pretrial Detention.” Pp. 129-51 in Punishing Poverty: How Bail and Pretrial Detention Fuel Inequalities in the Criminal Justice System, edited by C. S. Scott-Hayward and H. Fradella. Oakland, CA: University of California Press. https://doi .org/10.2307/j . ctvpb3wzb.7

Smith, Peter Scharff. 2006. "The Effects of Solitary Confinement on Prison Inmates: A Brief History and Review of the Literature." Crime $\mathcal{E}$ Justice 34(1):441-528. https: //doi.org/10.1086/500626

Smith, Peter Scharff. 2012. "A Critical Look at Scandanaivan Exceptionalism: Welfare State Theories, Penal Populism, and Prison Conditions in Denmark and Scandanavia." Pp. 38-57 in Penal Exceptionalism? Nordic Prison Policy and Practice, edited by T. Ugelvik and J. Dullum. London: Routledge.

Smith, Peter Scharff, and Janne Jakobsen. 2017. Når straffen rammer uskyldige. Børn affængslede i Danmark. Copenhagen: Gyldendal.

Spohn, Cassia. 2009. "Race, Sex, and Pretrial Detention." Kansas University Law Review 57:879-901.

Stevenson, Megan T. 2018. “Distortion of Justice: How the Inability to Pay Bail Affects Case Outcomes." Journal of Law, Econonics, and Organization 34(4):511-42. https : //doi .org/ 10.1093/jleo/ewy019

Sugie, Naomi R., and Kristin Turney. 2017. "Beyond Incarceration: Criminal Justice Contact and Mental Health." American Sociological Review 82(4):719-43. https://doi .org/10. 1177/0003122417713188

Toman, Elisa L., Joshua C. Cochran, and John K. Cochran. 2018. “Jailhouse Blues: The Adverse Effects of Pretrial Dentention on Prison Social Order." Criminal Justice and Behavior 45(3):316-39. https : //doi .org/10.1177/0093854817753018

Turney, Kristin, and Emma Connor. 2019. “Jail Incarceration: A Common and Consequential Form of Criminal Justice Contact." Annual Review of Criminology 2:1-26. https ://doi. org/10.1146/annurev-criminol-011518-024601 
Ulmer, Jeffrey T. 2012. "Recept Developments and New Directions in Sentencing Research." Justice Quarterly 29(1):1-40. https : //doi .org/10.1080/07418825.2011.624115

Wakefield, Sara, and Christopher Uggen. 2010. "Incarceration and Stratification." $A n$ nual Review of Sociology 36(1):387-406. https : //doi .org/10.1146/annurev . soc . 012809. 102551

Walmsley, Roy. 2016a. World Pre-trial/Remand Imprisonment List. 3rd ed. London: Institute for Criminal Policy Research.

Walmsley, Roy. 2016b. World Prison Population List. 11th ed. London: Institute for Criminal Policy Research.

Western, Bruce. 2006. Punishment and Inequality in America. New York: Russell Sage Foundation.

Wildeman, Christopher, and Lars H. Andersen. 2020. "Solitary Confinement Placement and Post-release Mortality Risk among Formerly Incarcerated Individuals: A Population-Based Study." Lancet Public Health 5(2):107-13. https : //doi .org/10. 1016/ S2468-2667 (19) 30271-3

Wildeman, Christopher, Signe Hald Andersen, Hedwig Lee, and Kristian Bernt Karlson. 2014. "Parental Incarceration and Child Mortality in Denmark." American Journal of Public Health 104(3):428-433. https: //doi .org/10.2105/AJPH. 2013.301590

Wildeman, Christopher, and Christopher Muller. 2012. "Mass Imprisonment and Inequality in Health and Family Life." Annual Review of Law and Social Science 8:11-30. https: //doi.org/10.1146/annurev-lawsocsci-102510-105459

Williams, Marian R. 2003. “The Effect of Pretrial Dentention on Imprisonment Decisions." Criminal Justice Review 28(2):299-316. https : //doi . org/10.1177/073401680302800206

Acknowledgments: We thank Robert Apel and Christopher Wildeman for helpful comments and the ROCKWOOL Foundation for their support of this research.

Sara Wakefield: School of Criminal Justice, Rutgers University, Newark. E-mail: sara.wakefield@rutgers.edu.

Lars Højsgaard Andersen: ROCKWOOL Foundation Research Unit.

E-mail: lha@rff.dk. 